\title{
THE INSTITUTE OF ACTUARIES
}

\section{MEMOIRS}

\section{GEOFFREY MARKS}

THE passing of Geoffrey Marks on 25 August I93 8 in his seventyfourth year has left a wide gap among the large circle of those who knew and respected him, and a sense of grievous loss among those who were privileged to be his friends.

Geoffrey Marks was a member of a family well known in Croydon in the latter half of last century. His father was a sherry shipper, and Geoffrey was the third of five brothers, two of whom now survive.

All five boys were educated at Whitgift Grammar School, and Geoffrey's was perhaps the most notable in the school record of a family all of whom did well. There was hardly any school activity during his period from $I 873$ to $I 882$ in which he did not play an outstanding part. Besides figuring frequently in prize lists, he won a junior scholarship and an exhibition, and was school captain in $188 \mathrm{I}-82$. He was one of the founders and, during his last three years, joint editor of the school magazine. At field sports and gymnastics he shone, but at no games so well as rugger and cricket, being Captain of both the school XV and XI. The school history, published long after, speaks of his cricket prowess: "Such excellent bats have been produced.as... G. Marks...." And again, "... was the first wicket-keeper of the eleven. Since his time several boys have occupied this position, but none of them have equalled G. Marks in point of excellence.... G. Marks has the honour of being the first boy to score over a hundred on behalf of the school. 'This he accomplished in I88I against the Whitgift Wanderers, making ro6."

This early prowess in sport continued in after years. In $188_{3}$, for instance, he won the open single-sticks competition at the German Gymnasium, and in I 884 a similar competition for broad-swords. He became a redoubtable "half" in the Croydon Rugby Club of which he was for a time captain; and he played regularly for the Whitgift Wanderers Cricket Club. Before giving up the game he achieved the distinction of being selected in 1894 and 1895 to keep wicket for Middlesex, and his curiously gnarled hands were a permanent reminder of his cricketing career.

After leaving school in I882 Geoffrey Marks entered the London office of the "Scottish Amicable" and so began a City career which was to cover the long span of over fifty years. Three years later in 1885 he joined the "Mutual", and in 1890 qualified as a Fellow of the Institute. While still under age 30 he was appointed in 1893 as Actuary and Chief Officer of the "Mutual". Upon the formation by amalgamation of the "National Mutual" in 1896 he became Actuary and Manager, and as 


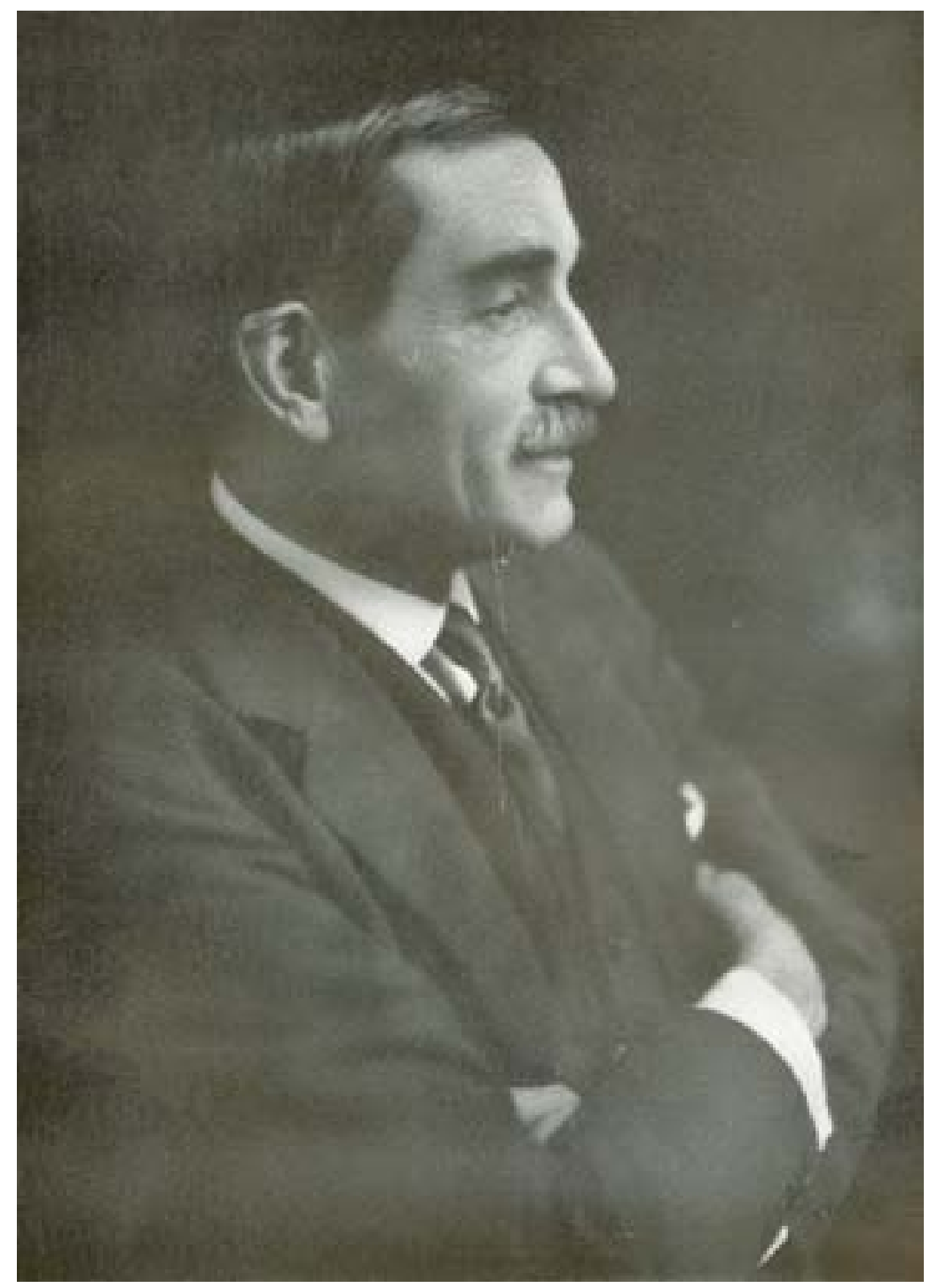

Geoffrey Marks, C.B.E.

Frontispiece 
Chief Officer and latterly as a director moulded the Society to his own fine pattern for the long period of thirty-six years. He retired in 1932 and was proud of the fact that, during the course of his career, he had occupied every public position of note which the insurance world could offer: President of the Institute of Actuaries 1918-20 (he was the doyen of the profession); Chairman of the Life Offices' Association I9I4-I6; Chairman of the British Insurance Association 1926. Only last year he retired from the chairmanship of the Unemployment Insurance Board which he had occupied with singular devotion and conspicuous success since its formation in $192 \mathrm{I}$.

Having achieved high office at so young an age, he later acquired an unrivalled experience of which he made full use as a member of innumerable committees and on more than one Government Royal Commission (Royal Commission on Decimal Coinage 1918-19 and Royal Commission on the Income Tax 1919-20). Intellectual integrity was his in full measure; he was a fearless intervener in debate, and there were in consequence few committees or bodies on which he served of which he did not quickly become a leading spirit.

It was thoroughly in keeping that he was the central figure on one unforgettable occasion at the Institute following on a long and rather tedious discussion which he had been asked to close. Upon at length being called upon he rose and said: "Gentlemen, I have been asked to close this discussion. The discussion is now closed!"- and immediately sat down again.

Over the years he was a worthy servant of the Institute; as Librarian from 1898 to 1910 ; as Examiner; Vice-President $19 \mathrm{I} I-13$; and finally as President 1918-20; while he served on the Council for the extraordinarily long period from 1896 to 1930 with only the breaks required by the Bye-Laws. He was a practical actuary, never a theoretical one; and his voice at the Institute was generally to be heard when financial and investment matters were under discussion. His professional reputation indeed rests less on his contributions to actuarial science than on his knowledge of the investment management of funds, and his skill and experience in this direction made him known and respected to a much wider circle than the purely insurance world. The Institute was fortunate in having his strong guiding hand as President during the time of anxiety coinciding with the termination of the War and the reconstruction period immediately following, when many difficult questions, connected with the resumption of the examinations in a modified form and with the reconstitution of the functions of the Institute in the new era, had to be determined. And it was during his term of office also that the decision was taken-revolutionary as it then seemed-to admit women to membership.

The War came upon him at an age when, to his own regret, active participation was no longer possible, but his services, particularly in 
connexion with the Navy and Army Canteen Board, led to the award in 1920 of a C.B.E.

Thus far the record is of a fine practical career and of material success. But Geoffrey's memory will remain dear not because of these things, which are open for all to read, but for his personal characteristics. For above all Geoffrey had a strong personality. In his youth this had found expression, as already described, in many forms of sport; and in middle life he added golf to his activities and in that game achieved a handicap of one. Sport in all its forms always roused his interest. Perhaps for this reason, too, youth had an irresistible appeal for him. Denied the blessing of a family himself, he was interested in a numerous succession of young people, whom he encouraged and helped and befriended; and it was typical of him that in later life he became a Governor of his old school, and so found yet another outlet for his interest in the coming generation. He had a rare judgment of men and things, and no actuary stood sponsor, during their early careers, to so many men who now occupy high positions in the insurance world. In his personal relationships he was quick and generous in his friendship; but he had an active temper, which, though quickly cooled, sometimes betrayed him in an impatience towards those to whom he did not extend his confidence. It was a trait to which his friends were well used, though it gained for him a reputation for being a somewhat formidable person. A characteristic personal foible was a tendency for flamboyancy in his dress, a liking for violent colours and in contrast.

$\mathrm{He}$ was that delightful combination of a successful man of business and a man of culture. An omnivorous reader over a catholic field with a predilection for the byways of literature, added to a keen and satirical sense of humour; these and a surprising knowledge of out-of-the-way things made him a charming companion to his intimates. He had, too, a scrupulous regard for the right use of language (slack punctuation would rouse him to fury), and his written word and professional contributions are models of precision and a delight to read. No one understood better the real value of things; the niceties of language and of conduct; a love for and appreciation of aesthetic values; an understanding, inherited perhaps from his father, of food and wine. He was in wine a connoisseur, and his dinner parties were a perfect exercise in gastronomy.

Geoffrey did not grow old gladly, and these last words are in tune with him:

"It is better to repose in the earth betimes than to sit up late; better, than to cling pertinaciously to what we feel crumbling under us, and to protract an inevitable fall. We may enjoy the present while we are insensible of infirmity and decay: but the present, like a note in music, is nothing but as it appertains to what is past and what is to come."

G. H. R. $16-2$ 